\title{
Improvement In Design \& Manufacturing Process of Multiple Spindle Drilling Attachment
}

\author{
Prof.M.B. Bankar ${ }^{1}$,Prof. P.B. Kadam ${ }^{2}$, Prof. M.R. Todkar ${ }^{3}$ \\ ${ }^{1}$ Assistant Professor, Mechanical Engineering Department, T.K.I.E.T.Warananagar, Tal. Panhala, Dist. \\ Kolhapur, India. \\ ${ }^{2}$ Assistant Professor, Mechanical Engineering Department, T.K.I.E.T.Warananagar, Tal. Panhala, Dist. \\ Kolhapur, India. \\ ${ }^{3}$ Assistant Professor, Mechanical Engineering Department, T.K.I.E.T.Warananagar, Tal. Panhala, Dist. \\ Kolhapur, India.
}

\begin{abstract}
In Indian manufacturing sector the growth of manufacturing depends largely on its productivity Drilling machine is used primarily in drilling holes, there are a few other functions that the multiple spindle drilling machine is capable of performing the functions include tapping, spot facing, reaming, countersinking, and counter boring to name a few. The multiple spindle drilling attachment performs basic drilling operations, there are some specific functions that are performed more accurately and conveniently. This attachment works mainly on planetary gear system arrangement. Multi Spindle Drilling Attachment Main function is more than one drilling operation at a time. It has many advantages like increase the production, decrease the operation time, reducing the labor cost, increase productivity and many more. Also reduce the cycles of operations. This is not possible if carry out the production by using general purpose machines.

Productivity and performance of the existing drilling machine will be increased by Design \& Manufacturing Process of Multiple Spindle Drilling Attachment. This paper deals with improvement in Design \& Manufacturing Process of Multiple Spindle Drilling Attachment for cycle time optimization of the component.
\end{abstract}

Keywords: Planetary gear system, Manufacturing, Multi-spindle Drilling Attachment, Gear.

\section{INTRODUCTION}

In the conventional manner only one job can be worked at a time for either of the above operations, but with increase in productivity demands a special purpose device or attachment is need which will increase productivity by,

1. Performing operations on more than one job at a time.

2. Performing multiple operations in one cycle.

3. Indexing capability to sequence operations one after another.

The Multi-spindle drilling attachment is an ideal solution to the above problem where in the conventional drilling machine is used to perform three operations at a time, so also different operations like drilling, reaming, countersinking or spot facing can be done simultaneously. The multi-spindle drilling attachment is easy to mount on the drilling machine, where in the MT-2 taper arbor directly fits into the drilling machine sleeve, if necessary an support sleeve can be attached to the top casing plate for extra stability. In the multi-spindle drilling attachment three spindle are driven simultaneously which carry three drill chucks. The drill chucks can receive twist drills, reamers, countersink drills or spot facing cutters to perform the desired operation.

\section{Various types of drilling attachment}

The various methods of multispindle drilling head are available for multi-drilling operation such as Adjustable multispindle drilling head \& Fixed Multispindle drilling head

Features of both the type multispindle drilling head are

1) By using these multispindle drilling heads, increase the productivity is substantial.

2) Time for one hole drilling is the time for multiple no. of holes drilling.

Here planetary gear system arrangement is selected for multispindle drilling attachment. 


\section{PRINCIPLE OF MULTIPLE SPINDLE DRILLING}

Torque is transmitted from sun gear to three planet gears for drilling purpose.

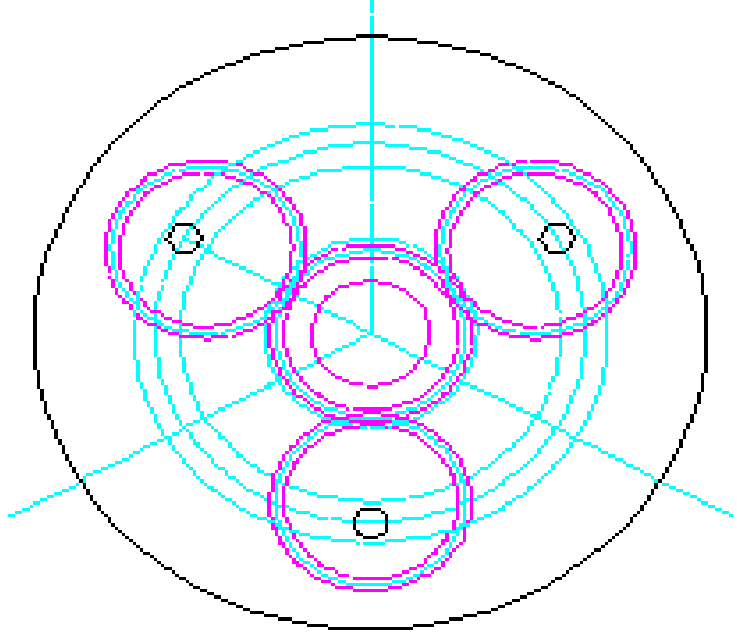

Fig 1.0 Principle of Multiple Spindle Drilling

There are three planet gears and one sun gear arrangement for transmitting the power from main spindle to planet shaft. . When machine is started the drilling machine spindle sleeve drives the arbor and thereby the planet gear system and the drill chucks and respective cutting tools, when the drilling machine spindle is fed in the downward direction the cutting action takes place. For enhancement and fast production an index able drill jig can be mounted on the drill machine table.

\section{DESIGN PROCEDURE}

In our attempt to design a special purpose machine we have adopted a very a very careful approach, the total design work has been divided into two parts mainly;

- System design

- Mechanical design

System design mainly concerns with the various physical constraints and ergonomics, space requirements, arrangement of various components on the main frame of machine no of controls position of these controls ease of maintenance scope of further improvement; height of $\mathrm{m} / \mathrm{c}$ from ground etc.

In Mechanical design the components are categoriesed in two parts.

- Design parts

- Parts to be purchased.

For design parts detail design is done and dimensions thus obtained are compared to next highest dimension which are readily available in market this simplifies the assembly as well as post production servicing work. The various tolerances on work pieces are specified in the manufacturing drawings. The process charts are prepared \& passed on to the manufacturing stage .The parts are to be purchased directly are specified \&selected from standard catalogues.

In system design we mainly concentrate on the following parameter such as System selection based on physical constraints, Arrangement of various components, Components of system, Chances of failure, Servicing facility, Height of $\mathrm{m} / \mathrm{c}$ from ground, Weight of machine.

\subsection{Motor Selection}

Thus selecting a motor of the following specifications

3 phase induction motor

Power $=0.5 \mathrm{hp}=375$ watt

Speed $=1440 \mathrm{rpm}$.

To calculate arbor Shaft Torque

POWER $=2 \Pi \mathrm{NT} / 60$

Motor is 375 watt power, run at 1440rpm, connected to drilling machine spindle by belt pulley arrangement of $1: 3$ ratio, considering $65 \%$ efficiency of belt drive, torque at the arbor shaft is given by,

Tmotor $\times 3 \times 0.65=2.48 \times 3 \times 0.65=4.84 \mathrm{~N}-\mathrm{m}$

Check for Tortional Shear Failure of Shaft 
Assuming minimum section diameter on input shaft $=16 \mathrm{~mm}$

$\Rightarrow \mathrm{d}=16 \mathrm{~mm}$

$\mathrm{Td}=\Pi / 16 \mathrm{x}$ fs act $\mathrm{x} \mathrm{d}^{3}$

$\Rightarrow \mathrm{fs}_{\text {act }}=$

$=\frac{16 \times 4.84 \times 10^{3}}{\Pi \times(16)^{3}}$

As fs ${ }_{\text {act }}<$ fs $_{\text {all }}$

$$
\Rightarrow \quad \mathrm{fs}_{\mathrm{act}}=6.01 \mathrm{~N} / \mathrm{mm}^{2}
$$

$\Rightarrow \mathrm{I} / \mathrm{P}$ shaft is safe under torsional load

\subsection{Design of key}

Minimum diameter of the shaft from standard data book is taken as $17 \mathrm{~mm}$ :

Key cross section: -

Width $=6$

Height $=6$

Material of key 'EN9'

Sult $=520 \mathrm{~N} / \mathrm{mm}^{2}$

Sylt $=340 \mathrm{~N} / \mathrm{mm}^{2}$

$\Rightarrow \mathrm{fs}_{\text {all }}=85 \mathrm{~N} / \mathrm{mm}^{2}$

$\Rightarrow \mathrm{fs}_{\text {all }}=170 \mathrm{~N} / \mathrm{mm}^{2}$

$\Rightarrow$ Selecting parallel key;

The following values shows the proportions of standard parallel keys, according to IS : 2292 and 2293-1974

(Reaffirmed 1992).

$6 \times 6 \times 30$

Check for direct shear failure of key:-

$$
\begin{aligned}
& \mathrm{T}=\mathrm{L} \times \mathrm{t} \times \mathrm{fs}_{\text {act }} \times \mathrm{d} / 2 \\
& \Rightarrow 4.84 \times 10^{3}=30 \times 6 \times \mathrm{fs}_{\text {act }} \times 17 / 2 \\
& \Rightarrow \mathrm{fs}_{\text {act }}=\frac{4.84 \times 10^{3} \times 2}{30 \times 6 \times 17} \\
& \Rightarrow \mathrm{fs}_{\text {act }}=3.16 \mathrm{~N} / \mathrm{mm}^{2} \\
& \text { As fs } \mathrm{fact}_{\text {all }}<\mathrm{fs}_{\text {all }}
\end{aligned}
$$

$\Rightarrow$ Key is safe under shear load

$>$ Check for crushing failure of key:-

$\mathrm{T}=\mathrm{L} \times$ fs $\mathrm{sct}_{\mathrm{ac}} \mathrm{d} / 2 \times \mathrm{t} / 2$

$4.84 \times 10^{3}=30 \times \mathrm{fs}_{\text {act }} \times 17 / 2 \times 6 / 2$

$\Rightarrow \mathrm{fs}_{\mathrm{act}}=\frac{4.84 \times 10^{3} \times 2 \times 2}{30 \times 17 \times 6}$

$\Rightarrow \mathrm{fs}_{\mathrm{act}}=6.33 \mathrm{~N} / \mathrm{mm}^{2}$

As $\mathrm{fs}_{\text {act }}<\mathrm{fs}_{\text {all }}$

$\Rightarrow$ Key is safe under crushing load

\subsection{Design of Planetary Spur Gear Box}

The multi spindle drilling attachment has an drive train in the form of planetary gear system comprising of the central sun gear and three planet gears which drive the three individual spindles on which drill chucks are mounted.

The following dimensions are assumed for the gear drive train,

Sun gear

Module $=1.5 \mathrm{~mm}$

No. of teeth $=32$

Planet gear

Module $=1.5 \mathrm{~mm}$

No. of teeth $=32$

Power $=0.5 \mathrm{HP}=375 \mathrm{watt}$

Speed $=480 \mathrm{rpm}$

$\mathrm{b}=10 \mathrm{~m}$

$\mathrm{T}$ design $=4.84 \mathrm{Nm}$ 
Sult pinion $=$ Sult gear $=600 \mathrm{~N} / \mathrm{mm}^{2}$

Service factor $(\mathrm{Cs})=1.5$

$\mathrm{dp}=48$

Now; $\mathrm{T}=\mathrm{Pt} \times \frac{\mathrm{dp}}{2}$

$\Rightarrow \mathrm{Pt}=\frac{2 \times 4.84 \times 10^{3}}{48}=201.6 \mathrm{~N}$.

Peff $=\left(\frac{\mathrm{Pt} \times \mathrm{Cs}}{\mathrm{Cv}}\right)=\left(\frac{\mathrm{Pt} \times 1.5}{\mathrm{Cv}}\right)$

Now;

$\mathrm{Cv}=\left(\frac{3}{3+\mathrm{v}}\right)$

$v=\frac{\Pi D N}{60 \times 10^{3}}=\frac{\Pi \times 48 \times 10^{-3} \times 480}{60}=1.2 \mathrm{~m} / \mathrm{sec}$

$\Rightarrow \mathrm{Cv}=0.71$

$\Rightarrow$ Peff $=\left(\frac{201.6 \times 1.5}{0.71}\right)$

Peff $=424 \mathrm{~N}$

Lewis Strength equation

WT $=$ Sbym

Where;

$\mathrm{Y}=0.484-2.86 / \mathrm{Z}$

$\Rightarrow \mathrm{yp}=0.484-\frac{2.86}{32} \quad=0.394$

$\Rightarrow$ Syp $=78.8$

Pinion and gear both are of same material and with same number of teeth hence

Syp $=$ Syg $=78.8$

$\mathrm{W}_{\mathrm{T}}=($ Syp $) \times \mathrm{b} \times \mathrm{m}$

$$
=78.8 \mathrm{x} 10 \mathrm{~m} \times \mathrm{m}
$$

$\mathrm{W}_{\mathrm{T}}=788 \mathrm{~m}^{2}$

Equation (A) \& (B)

$788 \mathrm{~m}^{2}=636$

$\Rightarrow \mathrm{m}=0.9$

Selecting standard module $=1.5 \mathrm{~mm}$

\section{Gear Data}

No. of teeth $=32$

Module $=1.5 \mathrm{~mm}$

Addendum $(\mathrm{m})=1.5 \mathrm{~mm}$

Dedendum $(1.25 \mathrm{~m})=1.88 \mathrm{~mm}$

Pitch Circle Diameter of Gear $=160 \mathrm{~mm}$

\subsection{ASME Code for Design of Shafts}

Since the loads on most shafts in connected machinery are not constant, it is necessary to make proper allowance for the harmful effects of load fluctuations According to ASME code permissible values of shear stress may be calculated form various relation.

$=0.18 \times 800$

$=144 \mathrm{~N} / \mathrm{mm}^{2}$

OR

fs ${ }_{\max }=0.3$ fyt

$=0.3 \times 680=204 \mathrm{~N} / \mathrm{mm}$

Considering minimum of the above values ;

$\Rightarrow \mathrm{fs}_{\max }=144 \mathrm{~N} / \mathrm{mm}^{2}$ 


\section{NOMENCLATURE}

$\mathrm{d}_{\mathrm{p}}=$ Diametral pitch

$\mathrm{m}=$ Module

$\mathrm{Td}=$ Tensional Shear Failure of Shaft

Tdesign $=$ Torsional load

$\mathrm{fs}_{\text {act }}=$ Actual shear stress

fs $_{\max }=$ Max. shear stress

$\mathrm{fs}_{\text {all }}=$ Allowable shear stress

$\mathrm{d}_{\text {= }}$ Minimum diameter of input shaft

Sult= Ultimate tensile strength

Sylt $=$ Yield tensile strength

Cs =Service factor

$\mathrm{Cv}=$ Velocity Factor

$\mathrm{Pt}=$ Tangential load

$\mathrm{b}=$ Face width $(\mathrm{mm})$

$\mathrm{dp}=$ Pitch circle diameter

Peff $=$ Effective load

WT $=$ Lewis Strength

$\mathrm{Y}=$ Lewis Form Factor

$\mathrm{Z}=$ Number of teeth

$\mathrm{P}=$ Power

5.Construction of Multispindle Drilling Attachment

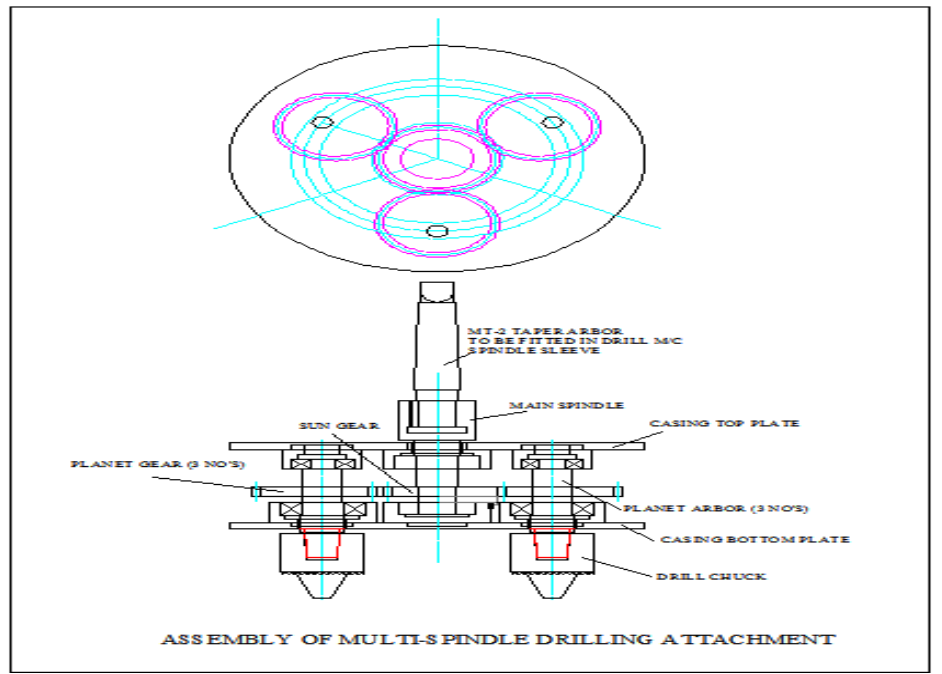

Fig.2.0

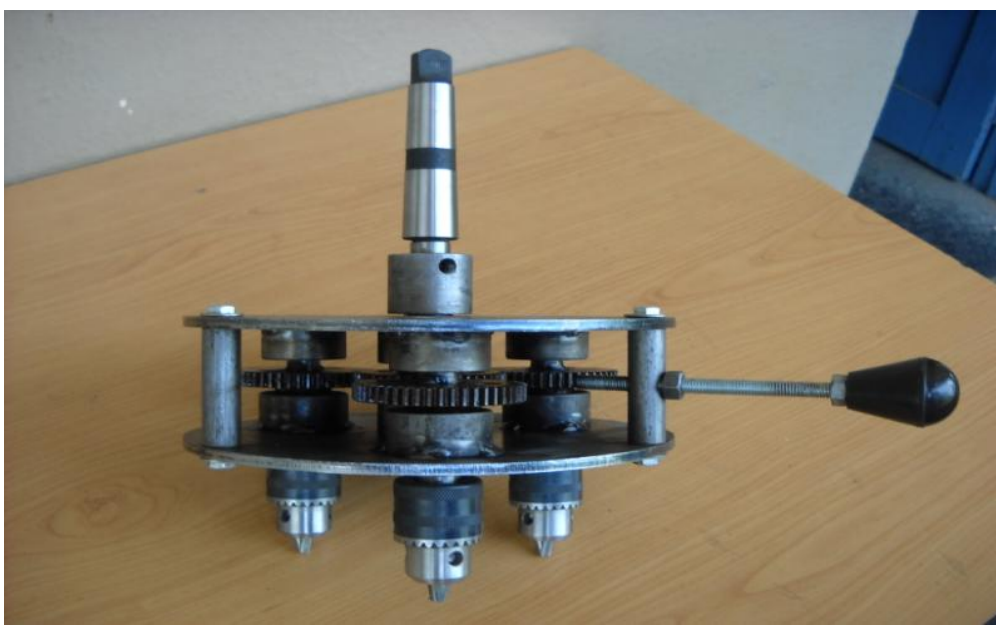

Fig.3.0 Main Assembly 
The multi-spindle drilling attachment is mounted on the drilling machine spindle sleeve, for extra stability an support sleeve may be mounted. The cutting tools as per the job requirements are mounted in the respective three drill chucks of the drilling attachment. When machine is started the drilling machine spindle sleeve drives the arbor and thereby the planet gear system and the drill chucks and respective cutting tools, when the drilling machine spindle is fed in the downward direction the cutting action takes place. For enhancement and fast production an indexable drill jig can be mounted on the drill machine table.

\section{VERIFICATION AND VALIDATION}

The results are implemented only in Design \& Manufacturing Process of multi spindle drilling attachment .This multi spindle drilling attachment is tested within in our college workshop for obtaining performance of this attachment and the performance is good. The performance of a this attachment often influences profitability or reputation of the end-user. As such, many specifications include damages related to inadequate performance.

\section{RESULTS AND DISCUSSION:}

Drilling is nothing but the use of a rotating multi-point drill to cut a round hole into a work piece. In a lot of manufacturing processes, one of the most indispensable machining tools is the multiple spindle drilling machine. The drilling machine is commonly called a drill press and is responsible for drilling various sizes of holes in any surface area and to precise depths. Aside from the fact the drilling machine is used primarily in drilling holes, there are a few other functions that the multiple spindle drilling machine is capable of performing. These functions include tapping, spot facing, reaming, countersinking, and counter boring to name a few.

There are four major categories of the drilling machine which include the upright sensitive drilling machine, upright drilling machine, radial drilling machine, and special purpose drilling machine. Although these multiple spindle drilling attachment perform basic drilling operations, there are some specific functions that are performed more accurately and conveniently by each of these types.

\section{CONCLUSION}

Using Multi-spindle Drilling Attachment, increase productivity at low cost and in less time. Also with the help of our equipment, reduce the cycles of operations. Although these multiple spindle drilling attachment perform basic drilling operations, there are some specific functions that are performed more accurately and conveniently by each of these types. For enhancement and fast production an indexable drill jig can be mounted on the drill machine table.

\section{ACKNOWLEDGEMENT}

I am thankful to my Co-author Prof. M.R.Todkar and Prof. P.B. Kadam in Mechanical Engineering Dept., TKIET, Warananagar, for their encouragement and support to carry out this work.

\section{REFERENCES}

[1] R.K.Jain and S.C. Gupta, "Production Technology", Khanna Publishers. $16^{\text {th }}$ Edition, 2001.

[2] "H.M.T. Production Technology - Handbook", Tata McGraw-Hill, 2000.

[3] V B Bhandari , "Design of machine elements" Tata McGraw Hill Publishing company limited"

[4] ASME Codes \& Standards

[5] Hajra Choudhury, "Elements of Workshop Technology", Vol. I and II, Media Promoters and Publishers Pvt., Ltd., Mumbai, 2005.

[6] M.D.-P.S.G.(Sixth Edition) )"Tata McGraw Hill Education Private Limited"

[7] M. Takalwe and V. R. Naik, "Design \& manufacturing of multi spindle drilling head (msdh) for its cycle time optimization (Vol 03, Issue 01; January-April 2012), International Journal of Mechanical Engineering applications Research - IJMEAR

[8] http://technicaljournals.org ISSN: 2249- 6564

[9] Groover M.P., (1996),Fundamentals of Modern Manufacturing, Materials, Processes and Systems ,International Editions,Prentice Hall. 